\title{
Functional outcome of auditory implants in hearing loss
}

\author{
S. Di Girolamo, A. Saccoccio, P. G. Giacomini, and F. Ottaviani \\ Otolaryngology Department, Policlinico Universitario Tor Vergata, University of Rome Tor Vergata, Rome, Italy
}

\section{Summary}

The auditory implant provides a new mechanism for hearing when hearing aid is not enough. It is the only medical technology able to functionally restore a human sense i.e. hearing. The auditory implant is very different from a hearing aid. Hearing aids amplify sound. Auditory implants compensate for damaged or non-working parts of the inner ear because they can directly stimulate the acoustic nerve. There are two principal types of auditory implant: the cochlear implant and the auditory brainstem implant. They have common basic characteristics, but different applications. A cochlear implant attempts to replace a function lost by the cochlea, usually due to an absence of functioning hair cells; the auditory brainstem implant $(\mathrm{ABD})$ is a modification of the cochlear implant, in which the electrode array is placed directly into the brain when the acoustic nerve is not anymore able to carry the auditory signal. Different types of deaf or severely hearing-impaired patients choose auditory implants. Both children and adults can be candidates for implants. The best age for implantation is still being debated, but most children who receive implants are between 2 and 6 years old. Earlier implantation seems to perform better thanks to neural plasticity. The decision to receive an implant should involve a discussion with many medical specialists and an experienced surgeon.

Keywords: Hearing aid; neuromodulation; auditory brainstem implant; ABI; cochlear implant.

\section{Introduction and history of auditory implants}

The history of auditory implants has been characterized by achieving a substantial growth in a relatively short period of time. The cochlear implants, are the result of intensive research over the last four decades. However, there is a long history of attempts to produce a hearing sensation by the electrical stimulation of the auditory system. The long-standing interest in the biological applications of electricity was the basis for the development of cochlear implants. The interest in the electrical methods of stimulating the hearing begins in the late 18 th century when Alessandro Volta discovered the electrolytic cell. Volta was the first to stimulate the auditory system electrically, by connecting a battery of
30 or 40 'couples' (approximately $50 \mathrm{~V}$ ) to two metal rods that were inserted into his ears. Crude applications of electrical stimulation were described through the 18th and 19th century in Paris, Amsterdam, London, and Berlin. The next step was taken by Duchenne of Boulogne who, in 1855 , stimulated the ear with an alternating current that he produced by inserting a vibrator into a circuit containing a condenser and induction coil. In 1868, Brenner published a more extensive investigation that studied the effects of altering the polarity, rate and intensity of the stimulus, and placement of the electrodes, on the hearing sensation produced. The initial optimism surrounding the bioelectrical approaches to cure deafness was followed by a period of scepticism, as the applications appeared to be invasive and required an ongoing critical evaluation. However, in the 1930's, interest on reproducing hearing artificially was renewed, due to the introduction of the thermionic valve, which allowed for the auditory system to be stimulated electrically with significantly greater precision.

Through the 1990s, clinical and basic science studies have resulted in progress in implant technology and in clinical approaches to auditory implants. Electrodes and speech processors now produce coding strategies that are associated with successively higher performance levels. Over the years, patients with implants have become more numerous and the risks have been minimized. More people have accepted that implants are here to stay, as implants are being increasingly recommended $[1,12,18,22]$.

\section{What is an auditory implant}

There are two principal types of auditory implant: the cochlear implant and the auditory brainstem implant. 


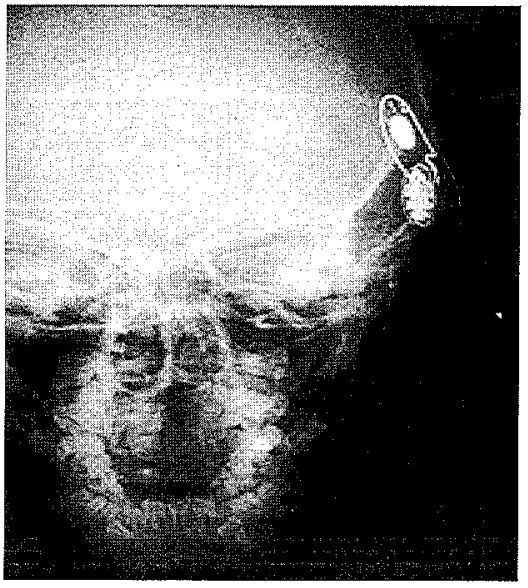

Fig. 1. Cochlear implant

They have common basic characteristics, but different applications. The cochlear implants (CI) (Fig. 1) are devices which replace damaged inner ear structures that have caused profound hearing loss. In the past, profound deafness was commonly referred to as nerve deafness. This was incorrect because the problem was not the hearing nerve, but the hair cells that line the cochlea. These hair cells are able to transform mechanical sound waves coming into the ear to electrical impulses that travel through nerves to the brain and are interpreted as sound. A cochlear implant, on the other hand, attempts to replace a function lost by the cochlea, usually due to an absence of functioning hair cells. In a normal hearing ear, the hair cells within the cochlea act as transducers of mechanical and hydraulic vibration of the tympanic membrane, ossicles of the middle ear, perilymph and endolymph of the inner ear, to chemo-electric energy capable of stimulating the eighth nerve. The decrease of hair cells results in the cochlea losing ability to stimulate the eighth nerve and leads to a sensory hearing loss. The cochlear implant replaces the function of the lost hair cells by converting mechanical energy (sound waves) into electrical energy capable of exciting the auditory nerve. Cochlear implants are surgically placed within the inner ear to bypass the hair cells of the cochlea and directly stimulate the endings of the auditory nerve. Although there have been many variations, the basic design of an implant system has remained relatively stable over the years.

The auditory brainstem implant (ABI) (Fig. 2) is a modification of the cochlear implant, in which the electrode array is placed directly in to the brain. Such a modified cochlear implant is intended to be used to stimulate the cochlear nucleus in the brainstem in patients

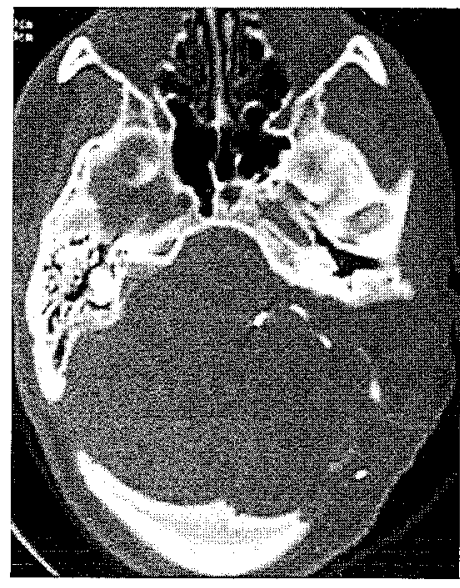

Fig. 2. Auditory brainstem implant

Table 1. Most frequent complications of cochlear implants

\begin{tabular}{|c|c|c|c|c|}
\hline Cause & $\begin{array}{l}\text { Frequency } \\
(\%)\end{array}$ & Type of comp & lications & \\
\hline $\begin{array}{l}\text { Wound- } \\
\text { related }\end{array}$ & 57 & infections & necrosis & $\begin{array}{l}\text { delay in wound } \\
\text { healing }\end{array}$ \\
\hline $\begin{array}{l}\text { Facial nerve- } \\
\text { related }\end{array}$ & 19 & $\begin{array}{l}\text { incorrect } \\
\text { stimulation }\end{array}$ & nerve lesion & \\
\hline $\begin{array}{l}\text { Electrode- } \\
\text { related }\end{array}$ & 13 & migration & $\begin{array}{l}\text { incorrect } \\
\text { position }\end{array}$ & $\begin{array}{l}\text { incorrect } \\
\text { compression }\end{array}$ \\
\hline Other & 11 & & 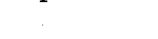 & \\
\hline
\end{tabular}

who have had their eighth nerves severed during surgery for removal of bilateral neurofibromas, as in patients with Neurofibromatosis type 2. The cochlear implant linear array of electrode contacts is replaced by a small rectangular silastic paddle containing the 21 contacts. This is surgically inserted into the lateral recess of the fourth ventricle. The need for this device is rare, but these patients are typically totally deaf and, although the benefit is not comparable to the cochlear implant results, most recipients derive significant auditory perception $[1,7,12,17,18,20,22]$.

\section{Components of the implant}

The implant consists of a microphone, a speech processor that acts as the hair cells changing acoustic energy into electrical-signals (analog or digital), a transmitter, and the implanted electrode component that contains a microchip that decodes and distributes the information along the cochlear nerve $(\mathrm{Cl})$ or on the cochlear nucleus (ABI). Depending on the sounds, the electrode delivers different stimuli to the VIII nerve or brainstem making deaf people hear a variety of sounds $[18,19,22]$. 


\section{Neural plasticity and the auditory implant}

The brain of a newborn can be compared to a new computer without its software or operating system installed. During both early fetal life and infancy, the auditory portion of the brain forms its neural connections, and learns how to process incoming sounds. Neurophysiologists consider the first few years of life as critical in establishing these connections because the brain is highly receptive to making new connections at this time; this is neural plasticity. Originally, implants were first allowed only in children four years of age or older. It has now become clear that the window of greatest hearing development may be the first two years of life, because of the high degree of neural plasticity. Children who are implanted earlier than two years of age seem to be able to "wire in" their neural connections with greater facility; the early results of cochlear implantation in very young children now appear to surpass those results obtained in older children. The age of implantation is a very important factor with great impact on each child's progress with his/her cochlear implant. Research and observation suggest that spoken language performance results are best for those who are implanted before the age of 3 years. This is the time when the brain most readily adapts and masters language. For children implanted at the youngest ages (prior to 18 months), spoken language appears to emerge most naturally. Based on the outcomes observed in many young implanted children, it appears that the stimulated sense of hearing offered through an auditory implant can offer an excellent opportunity for a child to progress in language "developmentally" rather than "remedially". The neural plasticity in children has a positive impact on the performance of a cochlear implant or even of an auditory brainstem implant; there are, however, many other factors impacting on performance: pre-implant duration of deafness, previous listening experience, status of cochlea or status of cochlear nucleus in the brainstem, cause of hearing loss, family support and motivation, quality and consistency of educational and rehabilitative environment $[2,3,5,15]$.

\section{Candidate selection for auditory implant}

A variety of requirements are considered in children and adults in order to determine candidacy for an auditory implant. These requirements continue to change, especially in relation to minimum age of implantation. Minimum age continues to be reduced due to the limited surgical risks and the improved outcomes of children implanted at younger ages. It is recommended that the preoperative process is based on a team approach that involves the family and professionals from both the medical and educational settings who are involved with the child. This will ensure that the child is an appropriate candidate for an auditory implant, that the family has realistic expectations regarding outcome, and that training and educational components are in place to assist and help the child to actualise the benefits from the implant. Obtaining accurate audiological information is the core of making appropriate recommendations related to implant candidacy. Since some audiological tests are more reliable and objective than others, obtaining a precise description of a child's hearing level requires a comprehensive audiological test battery completed by the examination of an experienced pediatric audiologist. The most widely accepted test batteries in auditory implant pre-operative patient assessment are:

1. Pure tone audiometry and/or behavioral audiometry for the search of the audiometric threshold.

2. Impedance audiometry, to exclude any middle ear pathology.

3. Speech discrimination test, to evaluate the intelligibility of the patient (the intelligibility expresses the intensity at whom the subject identifies $100 \%$ of presented words).

4. Otoacoustic emission, that verifies the sub-clinical cochlear damage.

5. Auditory brainstem response testing ( $A B R$ ) to assess retrocochlear function.

6. Nuclear magnetic resonance imaging of the brain (MRI).

In the case of a pediatric patient, who is not yet fully collaborating, the Behavioral Audiometry Test may be used instead of other tests, but above all we cannot be put aside from the ABR and from the MRI. It is important that the audiologist of the implant team is experienced in fitting and facilitating hearing aid use, making recommendations related to implantation, and fitting of the implant device following implantation so that any decision regarding implantation is made by the patient or the relatives following their complete information $[1,2,4,5,7,9,10,13,14]$. According to the results of the audiological tests described, we can select correctly the candidates for the auditory implant.

\section{Prerequisites of a candidate for a cochlear implant}

1) Adults and children with severe to profound sensorineural hearing loss in both ears.

2) Children who are 12 months (in certain cases, younger children may be selected) to 18 years of age and adults of any age. 
3) Individuals who receive insufficient benefit from hearing aids, i.e. with intelligibility inferior to $30 \%$.

4) Children who can receive family and educational support, because participation in the educational/ training programs is necessary in order to actualise benefit from the cochlear implant.

5) Individuals and families with appropriate expectations and an understanding of the necessary follow-up.

6) Individuals who are willing to wear the external apparatus.

\section{Who is not a candidate for a cochlear implant}

Certain characteristics of a child (or adult) make them unsuitable candidates for a cochlear implant. The unsuitable categories of children or adults include those who:

1) do not have the eighth nerve (auditory), which carries sound from the cochlea to the brain as determined by magnetic resonance imaging (MRI) during the candidacy pre-operative process;

2) have significant residual hearing levels and receive good benefit from traditional hearing aid devices;

3) have post-meningitis cochlear ossification or bilateral schwannoma.

Who is a candidate for auditory brainstem implant $(A B I)$

We consider an auditory brainstem implant (ABI) medically necessary in patients older than 12 years who have lost both auditory nerves due to disease (neurofibromatosis or von Recklinghausen's disease) $[5,6,10,13,15,16,18,22]$.

\section{Benefits and limitations of auditory implants}

A sensorineural auditory lesion constitutes a deficit only partially correctable with the acoustic prosthesis. A cochlear or auditory brainstem implant can provide access to sound by bypassing respectively the damaged hair cells in the cochlea or the cochlear nerve, thereby enabling the user to perceive sound; the implants convert sound into electrical signals and send these signals to the auditory nerve and to the brain; they provide more access to speech information than traditional hearing aids (digital or analogic) and provide improved speech perception for many children. Cochlear implants and auditory brainstem implants do not interpret sound $[1,5,7,12,18,22]$. However, with intensive training they can offer useful hearing and speech to a significant portion of profoundly deaf children.

\section{Results}

The outcomes of prelingually deaf children and postlingually deaf adults are fundamentally different. It is right to distinguish between these two categories of subjects: adults and children, because the procedure and the purpose for which the cochlear implant is applied are completely different. In adults with postlingual deafness, i.e. deaf after the acquisition of language, (usually language acquisition is complete after 4 or 5 years of age), the implant has the assignment to re-acquire a function previously possessed. In children deaf at the moment of birth or in children who became deaf in the first 3 years of life and were prevented from developing language (prelingual deafness), the implant has the assignment to support this development through a demanding and prolonged logopaedical assistance. In any case, the relatively older age in prelingually deaf children is not a contraindication but the potential for rehabilitation is smaller. Initially, implantations were usually performed in those who had become deaf after they had acquired speech (postlingual deafness). These individuals derived significant benefit from their auditory implants. Congenitally deaf children or adults, (deaf from birth), did not have as much success with the first implants. Currently, we are quite certain that prelingual deaf children or adults are good candidates for an implant and the younger a congenitally deaf child receives an auditory implant, the better the long-term results will be. Parents of children who receive $\mathrm{CI}$ or $\mathrm{ABI}$, must appreciate the considerable time commitment involved in the process of implantation and the required ongoing educational process. They must agree to return with the child to the implant center for follow-up testing and monitoring of the implant. The parents must also be willing to cooperate and work with the child's educators to provide appropriate re- habilitation $[4,8,9,11,12,20]$.

\section{Complications}

As with any surgical procedure, there are certain risks associated with $\mathrm{CI}$ or $\mathrm{ABI}$ surgery. In a literature review, the rate of surgical complications is about $2 \%$ in $\mathrm{CI}$, and higher in ABI surgery. Inner ear surgery carries the risk of damage to the balance organs or the facial nerve; this could lead to dizziness or a temporary or permanent facial paralysis. After surgery, it is possible that pro- 
blems could occur with the implanted device. Although the devices are extremely reliable, the electronic components could malfunction, or the implanted component could become infected or begin to extrude (come out through the skin). There may also be complications due to the electrical pulses delivered by the cochlear implant, for example facial nerve stimulation or other non-auditory sensation. This can usually be resolved by adjusting the programming of the speech processor $[10,13,19]$.

\section{References}

1. Bosman AJ, Snik AF, van der Pouw CT, Mylanus EA, Cremers CW (2001) Audiometric evaluation of bilateral fitted bone anchored hearing-aids. Audiology 40: 158-167

2. Brimacombe JA, Arndt PL, Staller SJ (1995) Multichannel cochlear implants in adults with residual hearing. Cochlear implants in adults and children, 100th NIH Consensus Development Conference, May 1995, Bethesda, MD, pp 31-35

3. Eisenberg LS (1982) Use of the cochlear implant by the prelingually deaf. Ann Otol Rhinol Laryngol 91 Suppl: 62-66

4. House WF, Berliner KI (1982) Cochlear implants: progress and perspectives. Ann Otol Rhinol Laryngol 91: 1-124

5. House WF, Urban J (1973) Long term results of electrode implantation and electronic stimulation of the cochlear in man. Ann Otol Rhinol Laryngol 82: 504-514

6. Leder SB, Spitzer JB, Flevaris-Phillips C, Kirchner JC, Milner P, Richardson F (1987) Innovative approaches to selection of cochlear implant candidates. J Rehabil Deaf 21: 27

7. Nikolopoulos T, Archbold S, O'Donoghue G (1999) The development of auditory perception in children following cochlear implantation. Int J Pediatr Otorhinolaryngol 49 Suppl 1: 189-191

8. Osberger MJ (1995) Speech perception in children. Cochlear implants in adults and children, 100th NIH Consensus Development Conference, May 1995, Bethesda, MD, pp 63-66

9. Owens E, Kessler DK (1989) Cochlear implants in young deaf children. College Hill, Boston
10. Kileny PR (1994) Use of electrophysiologic measures in the management of children with cochlear implants: brainstem, middle latency, and cognitive (P300) responses. Am J Otol 12: 37-47

11. Kileny PR, Zwolan TA, Zimmerman-Phillips S, Telian SA (1994) Electrically evoked auditory brainstem response in pediatric patients with cochlear implants. Arch Otolaryngol Head Neck Surg 120: 1083-1090

12. Rothera M, Conway M, Brightwell A, Graham J (1986) Evaluation of patient for cochlear implant by promontory stimulation. $\mathrm{Br} \mathrm{J}$ Aud 20: $25-28$

13. Shallop J, Arndt P, Tumacliff K (1992) Expanded indications for cochlear implantation: perceptual results in seven adults with residual hearing. J Speech Lang Pathol Audiol 16: 141-148

14. Shannon RV, Fayad J, Moore J, Lo WW, Otto S, Nelson RA, O'Leary M (1994) Auditory brainstem implant: II. Postsurgical issues and performance. Otoloaryngol Head Neck Surg 108: 634-642

15. Smith L, Simmons FB (1983) Estimating eighth nerve survival by electrical stimulation. Ann Otol Rhinol Laryngol 92: 19-23

16. Tyler RS, Preece JP, Lowder MW (1983) The Iowa cochlear implant tests. University of Iowa, Iowa City

17. Van der Pouw C (1998) Bone anchored hearing. Short and long term results. Thesis, The Netherlands, Nijmegen

18. Vermeulen AM, Beijk CM, Brokx JP, van den Borne $S$, van den Broek P (1995) Development of speech perception abilities of profound deaf children: a comparison between children with cochlear implants and those with conventional hearing aids. Ann Otol Rhinol Laryngol 104: 215-217

19. Waltzman SB, Cohen NL (2000) Cochlear implants. Thieme, New York

20. Waltzman SB, Fisher SG, Niparko JK, Cohen NL (1995) Predictors of postoperative performance with cochlear implants. Ann Otol Rhinol Laryngol 104 Suppl 65: 15-18

21. Wazen JJ, Spitzer J, Ghossaini SN, Kacker A, Zschommler A (2001) Results of the bone anchored hearing aid in unilateral hearing loss. Laryngoscope 111: 955-958

22. Weber BP, Dillo W, Dietrich B, Maneke I, Bertram B, Lenarz $\mathrm{T}$ (1998) Pediatric cochlear implantation in cochlear malformations. Am J Otol 19: 747-753

Correspondence: S. Di Girolamo, Department of Otolaryngology, Policlinico Universitario Tor Vergata, University of Rome Tor Vergata, Viale Oxford 81, 00133 Rome, Italy. e-mail: sdigirolamo@virgilio.it 